\title{
Acoustical and airflow considerations concerning double- layered façades with openings for natural ventilation
}

\author{
Ardeshir Mahdavi ${ }^{1, *}$, Shiva Najaf Khosravi ${ }^{1}$ \\ ${ }^{1}$ Department of Building Physics and Building Ecology, TU Vienna, Austria
}

\begin{abstract}
Numbers of factors such as noise exposure may constrain the use of natural ventilation, especially in the urban settings. Noise exposure was the motivation behind a previous research effort, recognizing that noise exposure hampers the operation of windows for natural ventilation. Thereby, specific designs of double-leaf façade solutions for concurrent natural ventilation and noise protection were empirically investigated. Tested variables included the position and size of the openings, the relative displacement of openings in the façade's two layers, as well as acoustical dampening (sound absorption) in the interstitial space between the two layers. The study of the models estimated the resulting sound insulation level of double-layered façades as a function of the aforementioned variables. In the present contribution, we further examine the airflow implications of the aforementioned double-façade configurations via computational fluid dynamic application based on a generic single-zone space. Natural ventilation efficiency in the building is evaluated by means of computed mean velocity and age of air inside the zone. High-resolution 3D steady CFD simulations of single-sided ventilation are performed for 9 configurations (sizes and positions) of the openings in the double-layered façade. The results illustrate the effects of these configuration on air flow circumstances in the test space.
\end{abstract}

\section{Introduction and background}

Typically, natural ventilation in buildings occurs through operation of inlets (usually windows) in buildings' envelope. As a high level of sound insulation of the building envelope is achieved when all windows are closed, natural ventilation requirements may be in conflict with noise protection requirements. Double-skin façades (DSF) may have the potential to offer some level of acoustical protection while accommodating natural ventilation. While aspects of building envelope acoustics and natural ventilation have been studied in the past (see, for example $[1,2,3,4,5,6,7,8,9]$, there is still a need for tools to support the design of envelope solutions that could address requirements pertaining to both natural ventilation and sound insulation.

To address this need, research efforts were conducted $[10,11,12,13,14]$ to better understand the potential of DSFs to support natural ventilation while maintaining some measure of acoustical insulation. Thereby, the influence of a number of factors (such as the geometric layout of the openings in the DSF's two layers and the deployment of acoustical absorption in the DSF's cavity) on the resulting sound insulation level was experimentally investigated. Specifically, calculations and laboratory measurements regarding the sound insulation of an experimental DSF with multiple opening configurations were compared. These efforts resulted in an empirically-based grey-box model for the estimation

\footnotetext{
* Corresponding author: amahdavi@tuwien.ac.at
}

of the sound insulation of double-facades with opening for natural ventilation (see section 2 below).

In the present contribution, we further explore the relationship between the levels of acoustical performance and ventilation performance. Toward this end, a computational approach was pursued, whereby the implications of various facade configurations for the resulting air flow in a generic single-zone space were investigated. Natural ventilation efficiency (in terms of mean age of air) in this space was obtained under assumed normalized mean wind speed and resulting pressure coefficients. High-resolution coupled (outdoor wind flow and indoor airflow) 3D steady RANS CFD simulations of single sided-ventilation were performed for 9 configurations (sizes and positions) of the openings in the facade's two layers (see section 3 below).

\section{The sound insulation estimation model}

To develop and test a model of DSFs' sound insulation, an experimental modular DSF with multiple opening possibilities was installed in a laboratory (see Figure 1) placed in the opening between two adjacent reverberant chambers. The wall segment consists of two layers of chip-board panels mounted on aluminium bars. Each layer has 25 dismountable square-shaped panels. Different numbers of elements can be opened in each layer, leading to different effective opening areas. 
Moreover, a number of elements embody smaller openings $(50 \%$ and $25 \%$ of the regular element's area). Given the flexibility of the grid structure, the distance (d) between openings (see Figure 2) and thus the respective view factor and angle of sound diffraction can be varied. Likewise, the amount and location of cavity absorption can be changed via installation of modular sound absorption elements.

Upon initial installation, the sound insulation of the construction was parametrically measured involving variations in opening size, displacement, and cavity absorption, resulting in frequency-dependent and weighted sound reduction index values. Altogether, 176 different configurations were empirically studied. Table 1 shows a sample of these configurations. The measurement results were expressed in terms of frequency-dependent $R_{f}$ and weighted $R_{w}$ sound reduction indices. These are basic measures of building components' sound insulation capability (see $[15,16]$ for more details).

\begin{tabular}{|l|l|l|l|l|l|}
\hline \multicolumn{1}{|l|}{1} & 2 & 3 & 4 & 5 \\
\hline 6 & 7 & 8 & 9 & 10 \\
\hline 11 & 12 & 13 & 14 & 15 \\
\hline 16 & 17 & 18 & 19 & 20 \\
\hline 21 & 22 & 23 & 24 & 25 \\
\hline
\end{tabular}

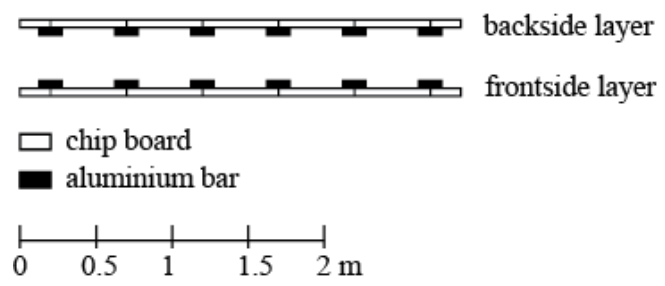

Fig. 1. Schematic illustration of the frontal view and plan of the experimental DSF.

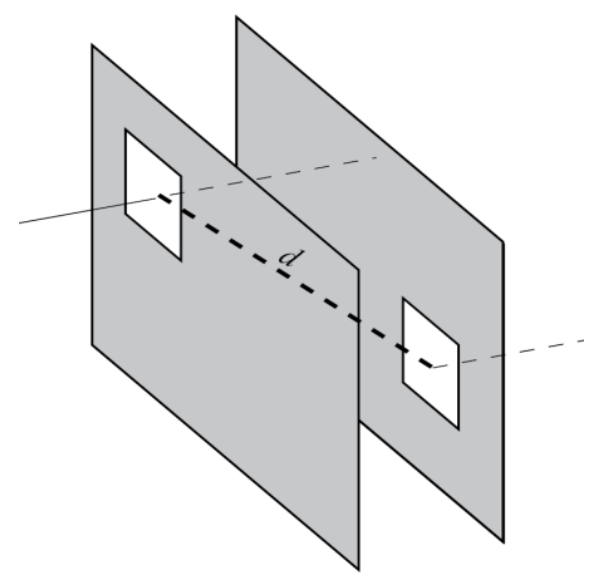

Fig. 2. Illustration of distance (d) between openings.
Table 1. Selected instances from the list of configurations of the experimental DSF (the codes of the openable elements are shown in Figure 1). Distance d is shown in Figure 2.

\begin{tabular}{cccc}
\hline $\begin{array}{c}\text { Config. } \\
\text { number }\end{array}$ & $\begin{array}{c}\text { Code of the open } \\
\text { element in layer } \\
\text { facing the source } \\
\text { room }\end{array}$ & $\begin{array}{c}\text { Code of the open } \\
\text { element in layer } \\
\text { facing the } \\
\text { receiver room }\end{array}$ & $\begin{array}{c}\text { Distance } \\
\mathbf{d}(\mathbf{m})\end{array}$ \\
\hline 1 & 1 & 1 & 0.43 \\
\hline 2 & 1 & 13 & 1.48 \\
\hline 3 & 1 & 25 & 2.86 \\
\hline 4 & 6,16 & 6,16 & 0.43 \\
\hline 5 & 6,16 & 8,18 & 1.09 \\
\hline 6 & 6,16 & 10,20 & 2.05 \\
\hline 7 & $1,6,11,16,21$ & $1,6,11,16,21$ & 0.43 \\
\hline 8 & $1,6,11,16,21$ & $3,8,13,18,23$ & 1.09 \\
\hline 9 & $1,6,11,16,21$ & $5,10,15,20,25$ & 2.05 \\
\hline
\end{tabular}

To process the parametric measurement results, we first considered the frequency-dependent reduction of the sound insulation index $\left(\Delta \mathrm{R}_{\mathrm{f}}\right)$ of the fully closed construction as a consequence of opening various elements in the experimental wall. The advantage of this indicator lies in its relative nature and hence the potential for generalisation. Specifically, the proposed reduction term denotes the difference between the frequencydependent sound insulation index (in $\mathrm{dB}$ ) of the fully closed configuration $\left(\mathrm{R}_{\mathrm{f}, \mathrm{max}}\right)$ and that of a specific configuration $\left(\mathrm{R}_{\mathrm{f}}\right)$ :

$$
\Delta R_{f}=R_{f, \max }-R_{f}
$$

The statistical analysis of the results ([14]) led to the following simple formula for the computation of $\Delta \mathrm{R}_{\mathrm{f}}$ :

$\Delta R_{f}=16.3 \cdot \log \left[f \cdot\left(1-\alpha_{m}\right) \cdot S_{F}(\log (V F \cdot 10000))^{0.5}\right][\mathrm{dB}]$

Here, $f$ denotes frequency in $\mathrm{Hz}, \mathrm{S}_{\mathrm{F}}$ denotes the area ratio of the opening area (toward the source room) and the wall's total area (i.e., $\mathrm{S}_{\text {open }} / \mathrm{S}_{\text {ref }}$ ), $\mathrm{VF}$ denotes the view factor (in sr) extended from the opening area in the source room to the opening area in the receiver room, and $\alpha_{\mathrm{m}}$ denotes the mean (area-weighted) cavity sound absorption. Given an obtained value for $\Delta \mathrm{R}_{\mathrm{f}}, \mathrm{R}_{\mathrm{f}}$ can be simply calculated by rearranging Eq. 1 :

$$
R_{f}=R_{f, \max }-\Delta R_{f}
$$

A predictive model for the reduction of the weighted sound reduction index $\left(\Delta \mathrm{R}_{\mathrm{w}}\right)$ of the fully closed DSF as a consequence of open elements can be established following a similar procedure. As such, this reduction term denotes the difference between the weighted insulation index of the fully closed configuration $\left(\mathrm{R}_{\mathrm{w}, \max }\right)$ and that of a specific configuration that includes openings $\left(\mathrm{R}_{\mathrm{w}}\right)$ :

$$
\Delta R_{w}=R_{w, \max }-R_{w}
$$


In this case, the statistical analysis of the results yielded the relationship expressed in equation 5. Note that both calculated and measured values of $\mathrm{R}_{\mathrm{W}}$ were derived from the frequency-dependent values according to the procedure specified in a pertinent international standard [16].

$R_{w}=10 \log \left[S_{F} \cdot V F^{0.5 \cdot}\left(1-\alpha_{m}\right)^{3}\right]+50$

Figure 3 illustrates the level of agreement between measured $\Delta \mathrm{R}_{w}$ values and those computed using equation 5 . Given a value for $\Delta R_{w}$, the respective value for $\mathrm{R}_{\mathrm{w}}$ can be obtained as follows:

$$
R_{w}=R_{w, \max }-\Delta R_{w}
$$

As mentioned before, the computed results ( $\mathrm{R}$ und $R_{w}$ values for configurations with openings) obtained from equations 3 and 6 were compared with laboratory measurements. Table 2 provides the results of the corresponding statistical assessment in terms of values for $\mathrm{R}^{2}$ (coefficient of determination) und RMSE (rootmean-square error).

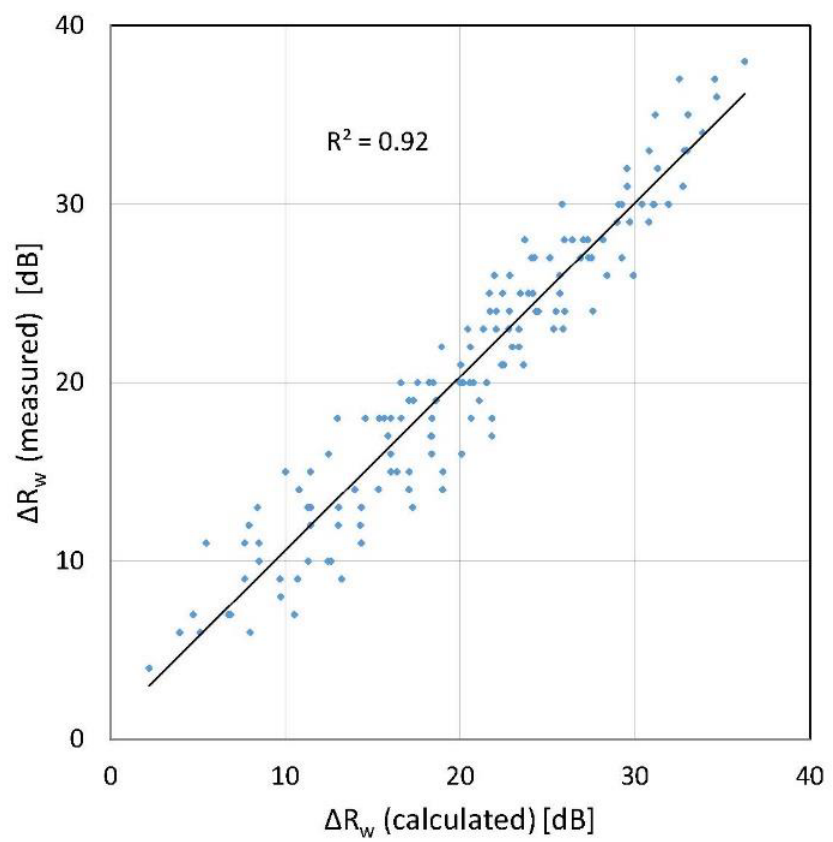

Fig. 3. Computed versus measured values of $\Delta R_{w}$

Table 2. Statistical comparison of computed and measured values of $R$ and $R_{W}$ via $R^{2}$ and $R M S E$.

\begin{tabular}{ccc}
\hline Computed parameter & $\mathbf{R}^{\mathbf{2}}$ & RMSE \\
\hline$\Delta \mathrm{R}_{\mathrm{f}}$ & 0.86 & 4.1 \\
\hline $\mathrm{R}_{\mathrm{f}}$ & 0.77 & 4.1 \\
\hline$\Delta \mathrm{R}_{\mathrm{w}}$ & 0.92 & 2.2 \\
\hline $\mathrm{R}_{\mathrm{w}}$ & 0.92 & 2.2 \\
\hline
\end{tabular}

Note that certain limitations apply while using the proposed formulas. Specifically, the weighted sound reduction index $R_{w}$ of the DSF under closed conditions must amount to at least $40 \mathrm{~dB}$. The ratio of the opening areas $\mathrm{S}_{\mathrm{F}}$ must be between 0.01 und 0.05. Likewise, the distance $\mathrm{d}$ between the opened elements should be at least $0.5 \mathrm{~m}$ and no larger than $3 \mathrm{~m}$. The distance D between the two layers should be between 0.3 and $1 \mathrm{~m}$.

\section{Airflow computation}

Air flow simulations were performed for a single-zone isolated building with an integrated double-leaf façade. The simulated space is $4 \mathrm{~m}$ wide, $5 \mathrm{~m}$ deep, and $3 \mathrm{~m}$ high. The modelled double façade configuration is consistent with the laboratory setting deployed for the aforementioned acoustical measurements (Fig. 1). In a five by five grid structure, each layer has 25 dismountable square elements $(50 \times 50 \mathrm{~cm})$, facing the approach flow. The upstream and downstream domain lengths are $5 \mathrm{H}$ and $10 \mathrm{H}$ respectively $(\mathrm{H}$ is the height of the building), based on the best practice guidelines by Franke et al. [17]. Figure 4 illustrates the computational domain. For wind speed a value of $6 \mathrm{~m} \cdot \mathrm{s}^{-1}$ was assumed at the height of $10 \mathrm{~m}$. The wind profile was obtained using the following equation:

$$
V_{z} \cdot V_{10^{-1}}=\left(Z \cdot 10^{-1}\right)^{a}
$$

Here, $\mathrm{V}_{\mathrm{z}}$ denotes air speed at height $\mathrm{Z}$ and $\mathrm{V}_{10}$ air speed at the height of $10 \mathrm{~m}$, and the exponent $a$ surface roughness ( 0.36 for urban area) [18]. The simulation was carried out for the wind direction normal to the building facade.

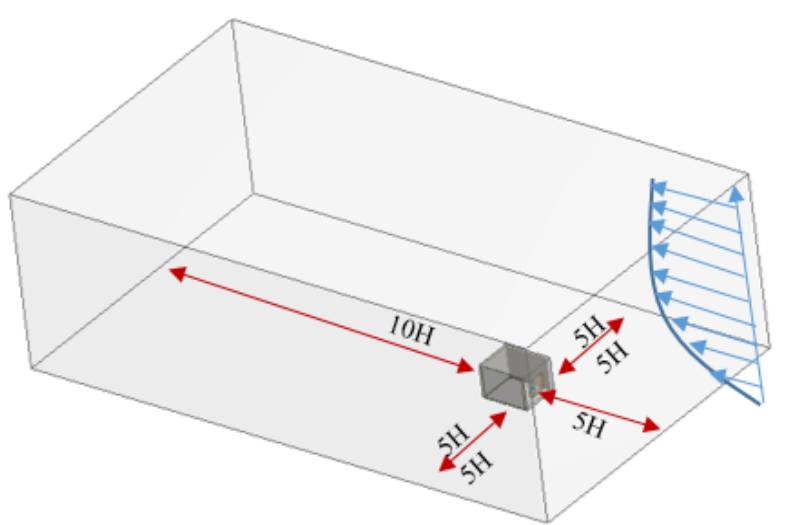

Fig.4. Perspective view of computational domain

Table 3. Boundary conditions for the analysis domain.

\begin{tabular}{cc}
\hline Inlet & See Eq. 7 \\
\hline outlet & $\begin{array}{c}\text { Zero static gauge } \\
\text { pressure }\end{array}$ \\
\hline $\begin{array}{c}\text { Upper and side boundary } \\
\text { Symmetry }\end{array}$ \\
\hline $\begin{array}{c}\text { Ground and building } \\
\text { surface }\end{array}$ & No-slip walls \\
\hline
\end{tabular}


The analysis was performed using the commercially available ANSYS FLUENT 19.1 CFD code [19]. The 3D steady RANS equations are solved in combination with the realizable k- $\varepsilon$ turbulence model by Shih et al. [20]. The SIMPLE algorithm is used for pressurevelocity coupling, pressure interpolation is second order and second-order discretization schemes are applied for both the convection and the viscous terms of the governing equations.

\section{Results and discussion}

Acoustical calculations and air flow simulations were conducted for the 9 double-façade configurations described in Table 1. As the key acoustical performance indicator, $\Delta \mathrm{R}_{\mathrm{w}}$ (see Eq. 4) denotes the reduction of weighted sound reduction index of a configuration as compared to the base case with both layers fully closed (see Table 4). The CFD simulation results were processed in terms of the mean air flow velocity and the mean age of air $\tau_{p}$ in the test space, which is a measure of the air freshness [21]. The local mean age of air was estimated by solving a user-defined scalar (UDS) transport equation. The diffusivity for the UDS transport equation was computed using the following equation:

$$
\tau_{p}=\left(2.88 \cdot 10^{-5}\right) \rho+\mu_{\text {eff }} S c_{t}{ }^{-1}
$$

Here, $\rho$ denotes the density of the air, $\mu_{e f f}$ the effective viscosity of the air, and $S C_{t}$ the turbulent Schmidt number ( $S C_{t}=1.2$ for natural ventilation) [22]. The boundary conditions for the UDS is set to 0 at the inlet and outlet openings of the domain. Second-order discretization is used for the convection and diffusion terms of the scalar transport equation. Table 4 entails a summary of the CFD simulation results for the aforementioned 9 configurations. Consideration of the computed age of air and air velocity data (see Table 4) does not reveal a linear relationship, but is consistent (higher mean air velocity values correspond to lower mean age of air values). Figure 5 further concerns the relationship between the pertinent acoustical parameter $\left(\Delta \mathrm{R}_{\mathrm{w}}\right)$ and the selected air flow parameter $\left(\tau_{\mathrm{p}}\right)$. However, in this figure, age of air is expressed logarithmically, so as to be consistent with the likewise logarithmic nature of sound insulation reduction values.

Table 4. Ventilation performance indicators for 9 configurations.

\begin{tabular}{cccc}
\hline Config. & $\begin{array}{c}\text { Mean Age of } \\
\text { air inside the } \\
\text { room [min] }\end{array}$ & $\begin{array}{c}\text { Mean velocity } \\
\text { inside the room } \\
{\left[\mathbf{c m . s}^{-1}\right]}\end{array}$ & $\begin{array}{c}\Delta \mathbf{R}_{\mathbf{w}} \\
{[\mathbf{d B}]}\end{array}$ \\
\hline 1 & 3.6 & 3.3 & 29 \\
\hline 2 & 10.8 & 0.9 & 20 \\
\hline 3 & 14.0 & 0.8 & 18 \\
\hline 4 & 2.7 & 4.7 & 33 \\
\hline 5 & 22.1 & 0.7 & 27 \\
\hline 6 & 35.1 & 0.5 & 25 \\
\hline 7 & 1.3 & 9.7 & 38 \\
\hline 8 & 8 & 1.7 & 33 \\
\hline 9 & 11 & 1.2 & 30 \\
\hline
\end{tabular}

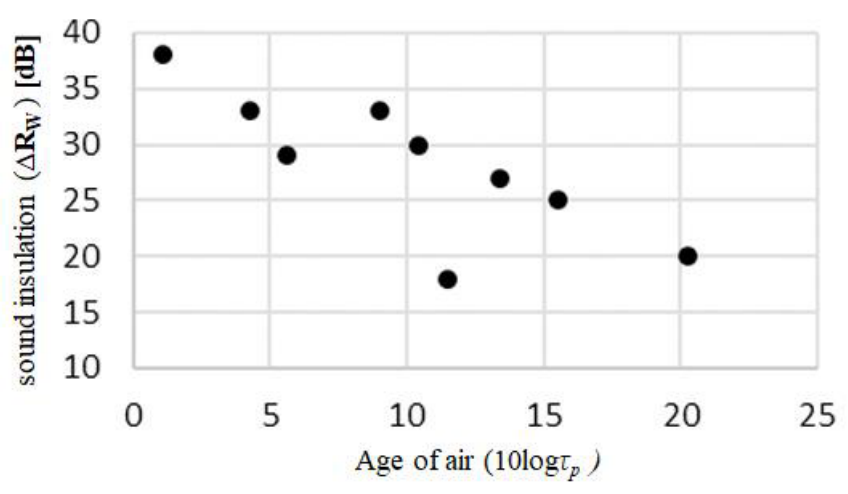

Fig.5. The relationship between measured $\Delta \mathrm{R}_{\mathrm{w}}$ and computed age of air for the selected 9 double-façade configurations.

The data summarized in this Figure appears to be plausible: Higher degrees of acoustical insulation correspond to lower levels of air freshness. However, the relationship between the measured $\Delta \mathrm{R}_{\mathrm{w}}$ and computed age of air values cannot be characterized in terms of a strong correlation. In other words, we cannot simply assume that a configuration with higher levels of sound insulation automatically translates in proportionally higher levels of air change. Specifically, configurations 3 appears to be somewhat of an outlier. In this particular configuration, the relatively large displacement might be responsible for a better than average acoustical performance.

To summarize, the acoustical measurements suggest that reasonable levels of sound insulation may be obtained from double-façade configurations, even if they involve openings for natural ventilation. Moreover, the derived grey box models allow for a fairly reliable estimation of the sound insulation levels based on a number of input variables related to the configuration at hand (e.g., opening area, opening displacement). However, the quantitative prediction of the levels of air change is non-trivial.

In the present contribution, only a subset of configurations could be computationally modelled for a restricted set of boundary conditions. Nonetheless, the results do not contradict the expectation that air flow indicators would correlate to acoustical ones.

In future efforts, we intend to further study this matter using both experimental and computational methods. Specifically, a larger number of configurations must be subjected to CFD simulation runs that take a variety of boundary conditions into account. Moreover, the impact of the stack effect - not considered in the present contribution - must be addressed. Likewise, the impact of air flow patterns need to be studied in configurations involving multiple coupled indoor spaces subject to both one-sided and cross ventilation. 


\section{References}

1. C. Buratti, Indoor noise reduction index with open window. Applied Acoustics 63, pp. 431-451(2002)

2. M.H. De Salis, D.J. Oldham, S. Sharples, Noise control strategies for naturally ventilated buildings. Building and Environment 37, pp. 471-484 (2002)

3. C.D. Field, F.R. Fricke. The attenuation of road traffic noise entering buildings through ventilation openings using quarter wave resonators: mechanism of attenuation and model experiments. Building Acoustics 2, pp. 625-35 (1995)

4. A. Khalegi, K. Bartlett, M. Hodgson. Relationship between ventilation, air quality and acoustics in 'green' and 'brown' buildings. 19th International Congress of Acoustics. Madrid (2007)

5. A. Mahdavi, Thermal and Acoustical Performance of "Buffer Rooms". ASHRAE Transactions 99, Part 1. pp.1092 - 1105 (1993)

6. J.P. Migneron, A. Potvin, Noise reduction of a double-skin facade considering opening for natural ventilation. Acoustics 2012 Hong Kong. J. Acoust. Soc. Am., 131, No. 4, Pt. 2, pp. 3320-3320 (2012)

7. Z. Nunes, B. Wilson, M. Rickard, An assessment of the acoustic performance of open windows, in line with ventilation requirements for natural ventilation. InterNoise (2010)

8. D.J. Oldham, M.H. De Salis, S. Sharples, Reducing the ingress of urban noise through natural ventilation openings. Indoor Air 14, pp. 118-126 (2004)

9. E.B. Viveiros, B.M. Gibbs, Sound insulation of ventilation louvres. Proceedings of Internoise 97. pp. 739-42 (1997)

10. A. Mahdavi, E. Bajraktari, M. Hintermayer, J. Lechleitner, Sound Insulation of Double Facades with Operable Windows: An Empirical Inquiry. CLIMA, World Congress. Society of Environmental Engineering, 1/1/1, Paper ID 275 (2013)

11. A. Mahdavi, O. Çakir, C. Pröglhöf, J. Lechleitner, Sound insulation of a double-leaf wall system with openings for natural ventilation. Proceedings of the 5th International Building Physics Conference Kyoto, Japan, pp. 1115 - 1118 (2012)

12. E. Bajraktari, J. Lechleitner, A. Mahdavi, The Sound Insulation of Double Facades with Openings for Natural Ventilation. Building Acoustics 22, 3and4; 163 - 176. (2015)

13. E. Bajraktari, J. Lechleitner, A. Mahdavi, Estimating the sound insulation of double facades with openings for natural ventilation. Energy Procedia 78, pp. 140-145(2015)

14. A. Mahdavi, E. Bajraktari, J. Lechleitner, U. Pont, Doppelfassaden mit Kombination von Schallschutz und (natürlicher) Lüftungsmöglichkeit. BauphysikKalender. N.A. Fouad (Ed.); Ernst \& Sohn, Verlag für Architektur und technische Wissenschaften, Berlin, ISBN: 9783433031698; pp. 531 - 542 (2017)
15. ISO EN ISO 10140-2: Acoustics - Laboratory measurement of sound insulation of building elements - Part 2: Measurement of airborne sound insulation (2010)

16. ISO EN ISO 717-1: Acoustics - Rating of sound insulation in buildings and of building elements Part 1: Airborne sound insulation (draft standard) (2011)

17. J. Franke, A. Hellsten, K.H. Schlunzen, B. Carissimo, The COST 732 Best Practice Guideline for CFD simulation of flows in the urban environment: a summary, International Journal of Environment and Pollution 44 (2011)

18. B. Blocken, J. Carmelit, Pedestrian Wind Environment around Buildings: Literature Review and Practical Examples, Journal of THERMAL ENV.\&BLDG. SCI. 28 (2004)

19. https://www.ansys.com/products/fluids

20. T.H. Shih, W. Liou, A. Shabbir, Z. Yang, J. Zhu, A new k- $\varepsilon$ eddy viscosity model for high Reynolds number turbulent flows, Computers and Fluids 24, Issue 3, pp. 227-238 (1995)

21. E. Mundt, H.M. Mathisen, P.V. Nielsen, A. Moser, Ventilation Effectiveness, Rehva Federation of European Heating and Air-conditioning Association GUIDEBOOK NO 2. (2004)

22. H. Montazeri, F. Montazeri. CFD simulation of cross-ventilation in buildings using rooftop windcatchers: Impact of outlet openings, Renewable Energy 118, pp. 502-520 (2018) 